\title{
Risk of stillbirth from occupational and residential exposures
}

\author{
Lisa M Pastore, Irva Hertz-Picciotto, James J Beaumont
}

\begin{abstract}
Objectives-To analyse the risk of stillbirth from 12 residential and occupational maternal exposures during pregnancy. Methods-Stillbirths and neonatal deaths in 1984 within 24 hours of birth from 10 California counties were identified from death certificates. Controls were randomly selected from live births born in 1984 and frequency matched to cases by maternal age and county. Data sources included vital statistics and a self administered postal questionnaire. Logistic regression and proportional hazards modelling were performed; the proportional hazards considered the truncated opportunity for exposure among cases. Special focus was given to two cause of death groups: congenital anomalies $(12 \%$ of deaths) and complications of the placenta, cord, and membranes $(37 \%$ of deaths).

Results-Occupational exposure to pesticides during the first two months of gestation was positively associated with stillbirths due to congenital anomalies (odds ratio (OR) 2.4, 95\% confidence interval (95\% CI) 1.0 to 5.9), and during the first and second trimesters with stillbirths due to all causes of death (risk ratios (RR) 1.3$1.4,95 \% \mathrm{CI} 1.0$ to 1.7 ) and stillbirths due to complications of the placenta, cord, and membranes (RR 1.6-1.7, 95\% CI 1.1 to 2.3). Occupational exposure to video display terminals in the third trimester was found to have a modest inverse association with stillbirths (RR 0.7, 95\% CI 0.6, 0.9). Home pesticide exposure was positively associated with stillbirths due to congenital anomalies (OR 1.7, 95\% CI 1.0 to 2.9).

Conclusions-Occupational exposure to pesticides, especially during early pregnancy, had a clear positive association with stillbirths regardless of cause of death. Methodologically, this study of stillbirths is unique in its analysis of specific causes of death and use of time specific exposure windows.
\end{abstract}

(Occup Environ Med 1997;54:511-518)

Keywords: fetal death; pesticides; survival analysis; epidemiology

In comparison with many reproductive outcomes-such as low birthweight or preterm delivery-stillbirths are rare. In 1989, the United States fetal death rate (fetal deaths of
20 weeks gestation or more per 1000 live births plus fetal deaths) was 7.5. ${ }^{1}$ In medical research, stillbirths are often combined with either spontaneous abortions to create one outcome of fetal death or combined with neonatal deaths to create one outcome of perinatal death. As a result, research on stillbirths alone among humans has been infrequently conducted and publications on associated risk factors are few.

For example, research on residential (as opposed to occupational) exposures is rare. No relevant studies on exposures to paint, lacquer, or varnish, nor proximity of households to commercial crops were identified. Maternal residential exposure to pesticides has been examined in a few studies ${ }^{2-5}$ and found to be positively associated with stillbirth.

More research has been réported on maternal occupational exposures than on residential exposures, particularly studies of pesticides and agricultural exposures. Positive associations with stillbirths were found in several studies with increased risk for female agricultural workers ranging from 1.4 -fold ${ }^{6}$ to 5.6-fold. ${ }^{7}$ Three of four studies on stillbirths and exposure to solvents found a generally positive association, ${ }^{7910}$ and the fourth ${ }^{11}$ found no association. The two studies that examined the relation between stillbirths and maternal occupational exposure to video display terminals $^{12}$ found non-significant inverse associations. The one published manuscript that investigated occupational exposure to extreme heat ${ }^{7}$ found a non-significant positive association with stillbirths. No relevant studies on maternal occupational exposure to disinfectants were identified.

This report considers the potential risk of stillbirth and neonatal death within 24 hours of birth (hereafter called stillbirths) from 12 self reported maternal occupational and residential exposures during pregnancy. Because stillbirths represent a likely aetiologically heterogeneous group of outcomes, special focus is given to two cause of death groups: congenital anomalies and complications of the placenta, cord, and membranes. Also, as monthly timing of exposures was available, time specific analyses were conducted. These more precise disease and exposure definitions were expected to yield improved risk estimates relative to earlier research.

\section{Materials and methods}

STUDY DESIGN

To investigate the association between stillbirths and several potential risk factors, a casecontrol study in 10 agricultural counties in 
Table 1 During your pregnancy, were you exposed to the following substances or conditions at your place of employment?

\begin{tabular}{|c|c|c|c|c|c|c|c|c|c|c|c|c|}
\hline \multicolumn{13}{|c|}{ Yes No } \\
\hline \multicolumn{13}{|c|}{$\begin{array}{l}\text { Extreme temperatures: } \\
\text { Heat (more } \\
\text { than } 100^{\circ} \mathrm{F}\end{array}$} \\
\hline $\begin{array}{l}\text { or } 38^{\circ} \mathrm{C} \text { ) } \\
\text { Cold (less } \\
\text { than } 32^{\circ} \mathrm{F}\end{array}$ & $\square$ & $\square$ & $\square$ & 1 & 2 & 3 & 4 & 5 & 6 & 7 & 8 & 9 \\
\hline or $0^{\circ} \mathrm{C}$ ) & $\square$ & 口 & $\square$ & 1 & 2 & 3 & 4 & 5 & 6 & 7 & 8 & 9 \\
\hline Pesticides & $\square$ & 口 & $\square$ & 1 & 2 & 3 & 4 & 5 & 6 & 7 & 8 & 9 \\
\hline terminals & 口 & 口 & ㅁ & 1 & 2 & 3 & 4 & 5 & 6 & 7 & 8 & 9 \\
\hline
\end{tabular}

California was initiated. Cases were defined as fetal deaths after 20 weeks of gestation and infant deaths within 24 hours of birth. California state law requires a certificate of fetal death if the gestation period is at least 20 weeks. Deaths that occurred within 24 hours of birth were included because many deaths that occur within minutes or hours after birth share aetiology with those born dead. A total of 642 cases delivered in 1984 were identified from fetal $(n=485)$ and infant $(n=157)$ death certificates from the 10 eligible counties. Twelve cases were subsequently found to be ineligible due to having occurred before 20 weeks of gestation or to having been therapeutically terminated, resulting in 630 cases. With a stratified random sample of live births born in the same year who survived more than 24 hours, a total of 642 controls were frequency matched to cases on county of maternal residence and maternal age (five age groups).

\section{DATA SOURCES}

Data abstracted from birth and fetal death certificates included delivery information, maternal and paternal demographic data, cause of death, and medical data from the pregnancy.

With the residential address on these certificates, an informed consent form and covering letter were posted to all 1272 identified women, followed by a self administered questionnaire. The time between delivery and completion of the questionnaire varied between two and four years. This delay was in part due to the time required within the state vital statistics system to create the electronic data tape used to ascertain addresses. The questionnaire considered the mother's medical and reproductive history before and during the pregnancy, occupational and residential exposures, drugs taken during the pregnancy, life events during the pregnancy, lifestyle exposures (smoking, sauna use), and a demographic profile. Month by month exposure information was asked for

Table 2 Percentage response among those located by race and ethnicity and case-control status, 10 counties in California, 1984

\begin{tabular}{lllllll}
\hline & $\begin{array}{l}\text { White, } \\
\text { non-Hispanic } \\
n=438\end{array}$ & $\begin{array}{l}\text { Hispanic, } \\
\text { any race } \\
n=175\end{array}$ & $\begin{array}{l}\text { Black } \\
n=34\end{array}$ & $\begin{array}{l}\text { Asian } \\
n=25\end{array}$ & $\begin{array}{l}\text { Other or } \\
\text { unknown race } \\
\text { or ethinicity } \\
n=17\end{array}$ & $\begin{array}{l}\text { Total } \\
n=689\end{array}$ \\
\hline Cases & 75 & 57 & 51 & 52 & 73 & 67 \\
Controls & 82 & 56 & 58 & 31 & 60 & 69 \\
Total & 78 & 56 & 54 & 39 & 68 & 68 \\
\hline
\end{tabular}

most, but not all, variables. Table 1 shows a sample question.

Both Spanish and English questionnaires were available. A $\$ 1$ note was included with the questionnaire as an incentive to reply. Nonresponders were followed up by a second letter, a third registered letter, and phone calls. Incorrect addresses were updated through the California Department of Motor Vehicles and a commercial subject location firm. Of the 1272 mothers identified, $80 \%$ could be located (79\% of cases and $81 \%$ of controls). Among women who were located, questionnaire response rates were $67 \%$ for cases and $69 \%$ for controls, resulting in 332 cases and 357 controls. These constituted the final population used in this analysis.

\section{DATA ANALYSIS}

This analysis focused on the association between stillbirths and occupational and residential factors for which the timing of exposures was available. Only those exposures that had at least 25 subjects (cases and controls combined) with exposure in at least one month and a minimum of 10 exposed cases and 10 exposed controls were included in the analysis. Exposure prevalences by trimester and any time during pregnancy were analysed. For all cases, crude odds ratios (ORs) for each potential risk factor were determined along with $95 \%$ confidence intervals ( $95 \% \mathrm{CIs}$ ).

Because stillbirths include a mix of aetiologically different pathways, the case population was subsequently restricted to two cause of death groups with international classification of diseases-ninth revision (ICD-9) codes from the death certificates: congenital anomalies (ICD-9 codes 740-759), and complications of the placenta, cord, or membranes (ICD-9 code 762). Congenital anomalies were evaluated to consider the potential association with exposures in the expected vulnerable time window of the first two months of pregnancy. ${ }^{8}$ Complications of the placenta, cord, or membranes were analysed because of the many cases in this cause of death group. Because the relevant timing of exposures and their effect on placenta, cord, and membrane complications is unknown, we analysed this case group in all trimesters.

With our month by month exposure data, we were able to investigate specific time periods during pregnancy which, aetiologically, might play a more important part in certain disease pathways. Although the monthly detail, theoretically, would allow us to fine tune the analysis to smaller time frames than trimesters, the relatively few exposed women and the correlation between consecutive months for residential and occupational exposures caused the monthly analysis to be unstable. Therefore, with the exception of the congenital anomaly case group, which used months 1 and 2 combined in the analysis, we show only the more stable trimester results.

Adjusted ORs or risk ratios (RRs) and 95\% CIs were calculated with logistic regression models for the congenital anomaly analysis, and proportional hazards models in all other 
Table 3 Distribution of maternal characteristics among cases and live birth controls: 10 counties in California, 1984

\begin{tabular}{|c|c|c|c|c|}
\hline & \multicolumn{2}{|l|}{ Cases } & \multicolumn{2}{|c|}{ Live birth controls } \\
\hline & $n$ & $(\%)$ & $n$ & $(\%)$ \\
\hline \multicolumn{3}{|l|}{ Maternal age: ${ }^{\star}$} & & $(100.0)$ \\
\hline $18-19$ & 25 & $(7.5)$ & 24 & $(6.7)$ \\
\hline $20-24$ & 103 & $(31.0)$ & 111 & (31.1) \\
\hline $25-29$ & 112 & (33.7) & 119 & (33.3) \\
\hline $30-34$ & 60 & (18.1) & 71 & (19.9) \\
\hline $35-39$ & 23 & $(6.9)$ & 27 & $(7.6)$ \\
\hline$\geqslant 40$ & 6 & $(1.8)$ & 4 & (1.1) \\
\hline Unknown & 3 & $(0.9)$ & 1 & $(0.3)$ \\
\hline \multicolumn{5}{|l|}{ Race and ethnicity:* } \\
\hline White non-Hispanic & 207 & $(62.3)$ & 236 & $(66.1)$ \\
\hline Hispanic & 85 & $(25.6)$ & 90 & $(25.2)$ \\
\hline Black non-Hispanic & 20 & $(6.0)$ & 14 & $(3.9)$ \\
\hline Asian & 15 & $(4.5)$ & 17 & $(4.8)$ \\
\hline Other & 5 & $(1.5)$ & 0 & $(0.0)$ \\
\hline \multicolumn{5}{|l|}{ Marital status: ${ }^{\star}$} \\
\hline Single & 41 & $(12.3)$ & 38 & $(10.6)$ \\
\hline Married & 273 & $(82.2)$ & 314 & $(88.0)$ \\
\hline Divorced & 7 & $(2.1)$ & 1 & $(0.3)$ \\
\hline Widowed & 1 & $(0.3)$ & 0 & $(0.0)$ \\
\hline Unknown & 10 & $(3.0)$ & 4 & (1.1) \\
\hline \multicolumn{5}{|l|}{ Parity:^ } \\
\hline 1 & 105 & $(31.6)$ & 126 & $(35.3)$ \\
\hline $2-3$ & 137 & $(41.3)$ & 178 & $(49.9)$ \\
\hline$\geqslant 4$ & 62 & $(18.7)$ & 51 & (14.3) \\
\hline Unknown & 28 & $(8.4)$ & 2 & $(0.6)$ \\
\hline Previous fetal loss & 86 & $(25.9)$ & 64 & $(17.9)$ \\
\hline \multicolumn{5}{|l|}{ Trimester prenatal care began:* } \\
\hline 1st & 222 & $(66.9)$ & 283 & $(79.3)$ \\
\hline 2nd & 62 & (18.7) & 62 & $(17.4)$ \\
\hline 3rd & 12 & (3.6) & 9 & $(2.5)$ \\
\hline None & 17 & $(5.1)$ & 1 & $(0.3)$ \\
\hline Unknown & 19 & $(5.7)$ & 2 & $(0.6)$ \\
\hline \multicolumn{5}{|c|}{ Smoked cigarettes during pregnancy: $†$} \\
\hline None & 249 & $(75.0)$ & 282 & $(79.0)$ \\
\hline$\leqslant 9 /$ day & 28 & $(8.4)$ & 27 & $(7.6)$ \\
\hline 10-19/day & 38 & (11.4) & 25 & $(7.0)$ \\
\hline$\geqslant 20 /$ day & 13 & $(3.9)$ & 18 & $(5.0)$ \\
\hline Unknown & 4 & $(1.2)$ & 5 & $(1.4)$ \\
\hline \multicolumn{5}{|l|}{ Alcohol use during pregnancy: $\nmid$} \\
\hline None & 236 & $(71.1)$ & 236 & $(66.1)$ \\
\hline$\leqslant 2 /$ week & 72 & $(21.7)$ & 87 & $(24.4)$ \\
\hline 3-6/week & 8 & $(2.4)$ & 14 & $(3.9)$ \\
\hline$\geqslant 1 /$ day & 10 & $(3.0)$ & 10 & $(2.8)$ \\
\hline Unknown & 6 & $(1.8)$ & 10 & $(2.8)$ \\
\hline Binge $(\geqslant 5$ in 1 day $)$ & 6 & $(1.8)$ & 14 & $(3.9)$ \\
\hline Employed during pregnancy† & 175 & $(52.7)$ & 203 & $(56.9)$ \\
\hline \multicolumn{5}{|l|}{ Education: ${ }^{\star \star}$} \\
\hline $0-11$ years & 85 & $(25.6)$ & 76 & $(21.3)$ \\
\hline High school degree & 101 & $(30.4)$ & 130 & (36.4) \\
\hline More than high school & 131 & $(39.5)$ & 139 & $(38.9)$ \\
\hline Unknown & 15 & $(4.5)$ & 12 & (3.4) \\
\hline \multicolumn{5}{|l|}{ Birth weight:* } \\
\hline$<1500 \mathrm{~g}$ & 172 & $(51.8)$ & 4 & $(1.1)$ \\
\hline $1500-2499 \mathrm{~g}$ & 69 & $(20.8)$ & 20 & $(5.6)$ \\
\hline $2500-3999 \mathrm{~g}$ & 61 & $(18.4)$ & 290 & $(81.2)$ \\
\hline$\geqslant 4000 \mathrm{~g}$ & 10 & $(3.0)$ & 43 & $(12.0)$ \\
\hline Unknown & 20 & $(6.0)$ & 0 & $(0.0)$ \\
\hline \multicolumn{5}{|l|}{ Gestational age: } \\
\hline$\leqslant 25$ weeks & 87 & $(26.2)$ & 0 & $(0.0)$ \\
\hline 26-34 weeks & 100 & (30.1) & 10 & $(2.8)$ \\
\hline 35-37 weeks & 41 & $(12.3)$ & 31 & $(8.7)$ \\
\hline$\geqslant 38$ weeks & 87 & $(26.2)$ & 305 & $(85.4)$ \\
\hline Unknown & 17 & $(5.1)$ & 11 & $(3.1)$ \\
\hline
\end{tabular}

${ }^{\star}$ Source $=$ birth certificate

†Source $=$ self administered questionnaire.

analyses. Models were produced for each individual exposure. Initial proportional hazards models included the trimesters as three variables simultaneously. However, because the residential and occupational factors were often present throughout pregnancy, ${ }^{14}$ collinearity between trimesters occurred and caused unstable models. Therefore, trimesters were subsequently modelled individually. The potential risk factors were coded to correspond with the number of months of exposure during the trimester-for example, potential risk factor would equal 2 if there were two months of exposure during the trimester-as a surrogate for dose.

In earlier work, one of us had shown the use of survival analysis to adjust for differing gestational ages at entry in clinic based studies of spontaneous abortion. ${ }^{15}$ The present paper shows the use of survival analysis, specifically proportional hazards models, to adjust for the different durations of gestation. Because cases tended to have shorter gestations, their probabilities of exposure were lower. ${ }^{14}$ If analyses do not adjust for person-time at risk, measures of association will be biased downward. (Poole ${ }^{16}$ showed that controlling for exposure opportunity is unnecessary when it is unrelated to the outcome. In the current study, duration of gestation, which represents exposure opportunity, is strongly related to the pregnancy outcome, and hence should be viewed as a confounder for which control is necessary to obtain unbiased measures of association.) Thus, a survival analysis was conducted in which cases (stillbirths and early neonatal deaths) were the events and the live births were removed from the risk set-that is, censored-at birth.

Proportional hazards models can be applied to case-control data wherein the randomly selected controls and a similar random sample of cases (with the same selection probability as the controls) serve as a subcohort, and the risk sets are constructed with those members of the subcohort who are still eligible to be a case at the time of each death. ${ }^{17}$ Partial likelihoods, the parameter estimates, and standard errors derived in this manner are as valid as those that would be based on a full cohort study. ${ }^{17}$ Our case-control data were transformed into a case-cohort study design as already described and the Epicure Peanuts software ${ }^{18}$ was used to calculate the risk estimates.

Potential confounders controlled in all models included smoking, alcohol use, maternal race and ethnicity, maternal age, county of residence, and earlier pregnancy loss. Season of conception was also included in the models for residential and occupational pesticides. Per capita income was included in the model for occupational exposure to a video display terminal. For the congenital anomaly models, the smoking and alcohol variables represented use any time in the first two months of pregnancy; for all other analyses, the variables represented use any time during the pregnancy. Maternal age and county of residence were controlled because the study design involved frequency matching on these variables. Maternal age is also a risk factor based on some previous research, ${ }^{6-21}$ but not all. ${ }^{22}$ Although low education has been found to be a risk factor in earlier research, ${ }^{21}$ it was not associated with case-control status in our data (table 2). Maternal race and ethnicity, age, county, and season of conception were each coded as a set of dichotomous variables, per capita income as a continuous variable, and all other confounders as single dichotomous variables.

All covariates were tested for the proportional hazards assumptions with log cumulative hazard function graphs. The variable 
Table 4 Prevalence (\%) of potential risk factors any time during pregnancy and by trimester: 10 counties in California, 1984

\begin{tabular}{|c|c|c|c|c|c|c|c|c|}
\hline & \multicolumn{2}{|c|}{$\begin{array}{l}\text { Any time during } \\
\text { pregnancy }\end{array}$} & \multicolumn{2}{|c|}{ 1st Trimester } & \multicolumn{2}{|c|}{$\begin{array}{l}\text { 2nd } \\
\text { Trimester }\end{array}$} & \multicolumn{2}{|c|}{ 3rd Trimester } \\
\hline & Cases & Controls & Cases & Controls & Cases & $\overline{\text { Controls }}$ & Cases" & $\overline{\text { Controls }}$ \\
\hline \multicolumn{9}{|l|}{ Residential exposures: } \\
\hline $\begin{array}{l}\text { Home pesticide } \\
\text { application } \dagger \\
\text { Lived }<0.25 \text { miles }\end{array}$ & 29.2 & 28.3 & 13.3 & 9.0 & 14.8 & 16.2 & 11.8 & 11.2 \\
\hline from crops & 23.5 & 21.8 & 19.6 & 14.3 & 20.2 & 16.0 & 20.8 & 17.4 \\
\hline $\begin{array}{l}\text { Paint application } \\
\text { Lived } 0.25-1 \text { mile }\end{array}$ & 13.0 & 19.3 & 3.6 & 3.4 & 7.8 & 9.5 & 5.7 & 9.2 \\
\hline from crops & 17.5 & 18.5 & 12.7 & 15.1 & 14.2 & 14.6 & 17.0 & 15.7 \\
\hline $\begin{array}{l}\text { Garden pesticide } \\
\text { application }\end{array}$ & 12.3 & 16.0 & 6.0 & 6.4 & 6.6 & 9.0 & 4.7 & 7.8 \\
\hline $\begin{array}{l}\text { Pet pesticide } \\
\text { application }\end{array}$ & 11.4 & 12.9 & 5.1 & 3.9 & 7.8 & 7.0 & 6.6 & 5.9 \\
\hline $\begin{array}{l}\text { Lacquer or varnish } \\
\text { application }\end{array}$ & 3.6 & 4.5 & 1.2 & 0.6 & 1.8 & 0.6 & 2.8 & 3.4 \\
\hline $\begin{array}{l}\text { Occupational exposures: } \\
\text { Video display }\end{array}$ & & & & & & & & \\
\hline terminals & 6.6 & 10.4 & 4.5 & 7.8 & 4.5 & 8.7 & 3.3 & 7.0 \\
\hline Extreme heat & 4.5 & 9.0 & 2.1 & 3.9 & 3.0 & 4.8 & 1.4 & 4.8 \\
\hline Disinfectants & 6.6 & 5.0 & 4.2 & 3.6 & 3.6 & 3.6 & 2.4 & 3.1 \\
\hline Solvents or degreasers & 3.0 & 4.2 & 1.5 & 2.8 & 1.5 & 2.0 & 0.0 & 1.1 \\
\hline Pesticides & 5.4 & 3.6 & 3.6 & 1.1 & 3.0 & 1.7 & 0.9 & 1.1 \\
\hline $\begin{array}{l}\text { Denominator number of } \\
\text { cases or controls }\end{array}$ & 332 & 357 & 332 & 357 & 332 & 357 & $212^{\star}$ & 357 \\
\hline
\end{tabular}

$\star$ Relative to the 212 cases whose pregnancy completed six full months of gestation †Pesticides for ants, cockroaches, etc.

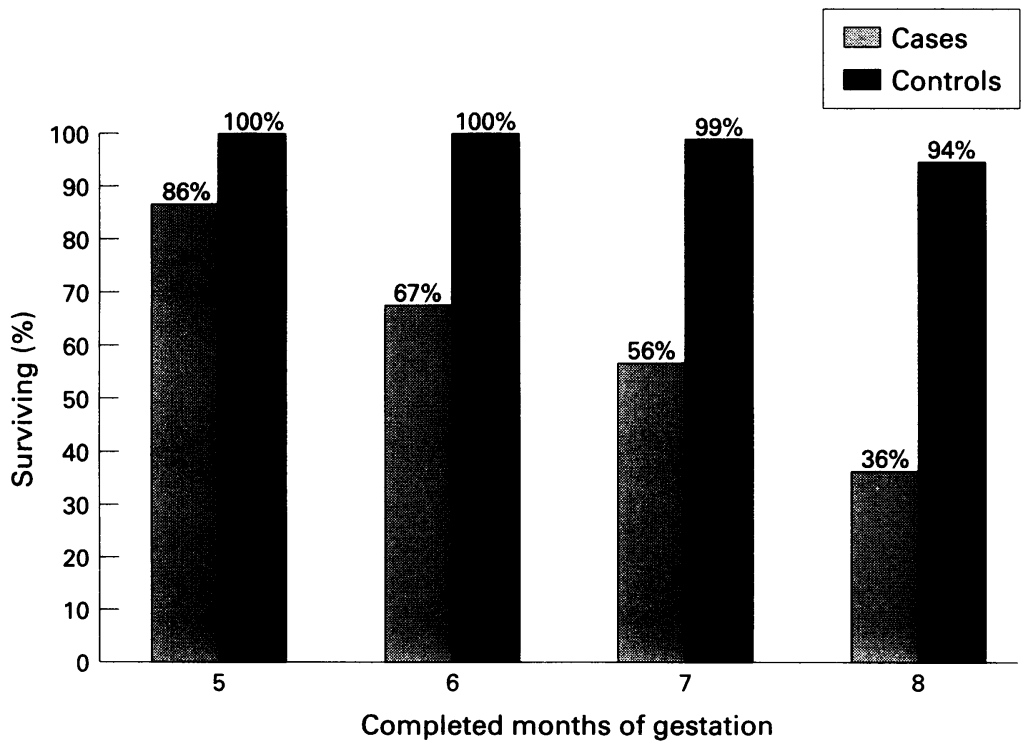

Exposure opportunity differential between cases and controls in 10 counties in California, 1984.

representing earlier fetal loss was the only covariate that violated the proportional hazards assumptions. Thus, this variable was recoded to account for the interaction with time at the point of deviance between the two plotted curves (rounded upward to the next half month so as to have adequate numbers in each cell), which was at the gestational age of 5.5 months.

\section{Results}

By case status, the average ages of responders, non-responders, and non-located women were similar (range of 25.3 to 26.6 years). Among cases, there was virtually no difference in the cause of death distributions by response status. Differences in race and ethnicity by response status (table 2) were found. The proportion of cases who responded was slightly less than the proportion for controls among white nonHispanic and black women. Among Asian, other, and unknown race or ethnicity groups the proportion of cases who responded was at least 10 percentage points higher than for controls. The proportions who responded were not different between cases and controls, both overall and for Hispanic women.

Age, race and ethnicity, marital status, employment during pregnancy, and education did not differ between cases and controls (table 3). On average, controls entered prenatal care earlier. Cases had higher rates of previous fetal loss and higher parity. The distributions of birthweight and gestational age for the pregnancy of interest were different, by definition, for cases and controls.

Of the potential risk factors we examined, home use of pesticides (pesticides for control of ants, cockroaches, etc) was the most prevalent exposure $(28 \%-29 \%)$ for both cases and controls any time during pregnancy (table 4), followed by living less than a quarter of a mile from commercial crops $(22 \%-24 \%)$. These two exposures, plus living from a quarter of a mile to a mile from commercial crops, were the top three exposures by trimester for both cases and controls. In general, the occupational exposures were less common than the residential exposures. Among controls, video display terminals had the highest prevalence of the occupational exposures in all periods. Among cases, none of the occupational exposures was particularly more prevalent than the others.

The figure shows the truncated opportunity for exposure among stillbirths in months 6-9. As shown, only $36 \%$ of the stillbirths had gestations that survived eight full months versus $94 \%$ of controls. The differential exposure opportunity highlights the need for time dependent analyses most notably for third trimester exposures as relative risks comparing cases with controls for exposures in the third trimester would clearly be biased downward if survival time was not considered. Similarly, second trimester crude ORs would also be biased downward, but to a lesser extent.

Because of this differential exposure opportunity, all further analyses were adjusted for exposure opportunity. For all causes of death combined (table 5), occupational exposure to pesticides showed a positive association with stillbirths in the first and second trimesters which was significant at $P<0.05$. Women occupationally exposed to pesticides for one month in the first trimester had 1.4 times the risk of stillbirth of unexposed women, whereas those exposed for all three months in the trimester had 2.7 times the risk. The associations in the second trimester were only slightly less than those in the first trimester. A modest inverse association ( $R R \quad 0.7$ ) was found for occupational exposure in the third trimester to video display terminals. An inverse association of borderline stability was also found for occupational exposure to extreme heat in the first and third trimesters ( $R R$ 0.7). All other exposures yielded results close to the null.

Table 6 contains cause of death distributions for (a) cases who responded, (b) all cases including those not located and those who did not respond to the questionnaire, and (c) 
Table 5 Adjusted association of exposures by individual trimester for all causes of stillbirth: 10 counties in California, 1984

\begin{tabular}{|c|c|c|c|}
\hline Exposure factors & Trimester & $\begin{array}{l}\text { Adjusted RR for } 1 \text { month } \\
\text { of exposure } \\
(95 \% \text { CI) }\end{array}$ & $\begin{array}{l}\text { Adjusted } R R \text { for } 3 \\
\text { months of exposure } \\
(95 \% \text { CI) }\end{array}$ \\
\hline \multicolumn{4}{|l|}{ Residential exposures: } \\
\hline \multirow{3}{*}{ Home pesticide application $†$} & 1 & $1.1(1.0$ to 1.3$)$ & $1.4(0.9$ to 2.3$)$ \\
\hline & 2 & $1.0(0.8$ to 1.1$)$ & $0.9(0.6$ to 1.5$)$ \\
\hline & 3 & $0.9(0.8$ to 1.0$)$ & $0.8(0.5$ to 1.1$)$ \\
\hline \multirow[t]{3}{*}{ Lived $<0.25$ miles from crops $\oint$} & 1 & $1.0(1.0$ to 1.1$)$ & $1.0(0.9$ to 1.2$)$ \\
\hline & 2 & $1.0(1.0$ to 1.1$)$ & $1.1(1.0$ to 1.2$)$ \\
\hline & 3 & $1.0(0.9$ to 1.1$)$ & $1.0(0.8$ to 1.2$)$ \\
\hline \multirow[t]{3}{*}{ Paint application } & 1 & $1.0(0.7$ to 1.4$)$ & $1.0(0.4$ to 2.7$)$ \\
\hline & 2 & $0.9(0.7$ to 1.2$)$ & $0.8(0.4$ to 1.8$)$ \\
\hline & 3 & $0.9(0.7$ to 1.1$)$ & $0.7(0.4$ to 1.3$)$ \\
\hline \multirow{3}{*}{ Lived $0.25-1$ mile from crops $\oint$} & 1 & $1.0(1.0$ to 1.1$)$ & $1.1(1.0$ to 1.2$)$ \\
\hline & 2 & $1.0(1.0$ to 1.1$)$ & $1.1(1.0$ to 1.2$)$ \\
\hline & 3 & $1.0(0.9$ to 1.1$)$ & $0.9(0.7$ to 1.2$)$ \\
\hline \multirow[t]{3}{*}{ Garden pesticide application } & 1 & $0.9(0.8$ to 1.2$)$ & $0.7(0.5$ to 1.7$)$ \\
\hline & 2 & $0.9(0.7$ to 1.1$)$ & $0.7(0.4$ to 1.4$)$ \\
\hline & 3 & $0.9(0.7$ to 1.0$)$ & $0.7(0.4$ to 1.1$)$ \\
\hline \multirow{3}{*}{ Pet pesticide application } & 1 & $1.0(0.8$ to 1.2$)$ & $1.0(0.5$ to 1.9$)$ \\
\hline & 2 & $1.0(0.8$ to 1.2$)$ & $1.0(0.5$ to 1.8$)$ \\
\hline & 3 & $1.0(0.8$ to 1.1$)$ & $0.9(0.6$ to 1.4$)$ \\
\hline \multirow[t]{3}{*}{ Lacquer or varnish application } & 1 & $1.2(0.7$ to 2.1$)$ & $1.8(0.3$ to 9.6$)$ \\
\hline & 2 & $1.0(0.6$ to 1.8$)$ & $1.0(0.2$ to 5.5$)$ \\
\hline & 3 & $1.0(0.8$ to 1.3$)$ & $1.0(0.4$ to 2.2$)$ \\
\hline \multicolumn{4}{|l|}{ Occupational exposures: } \\
\hline \multirow[t]{3}{*}{ Video display terminals } & 1 & $0.9(0.7$ to 1.0$)$ & $0.6(0.3$ to 1.1$)$ \\
\hline & 2 & $0.8(0.7 \text { to } 1.0)^{\star}$ & $0.5(0.3 \text { to } 1.0)^{\star}$ \\
\hline & 3 & $0.7(0.6 \text { to } 0.9)^{\star \star}$ & $0.4(0.2 \text { to } 0.8)^{\star \star}$ \\
\hline \multirow[t]{3}{*}{ Extreme heat } & 1 & $0.7(0.5$ to 1.1$)$ & $0.4(0.1$ to 1.3$)$ \\
\hline & 2 & $1.0(0.7$ to 1.3$)$ & $0.9(0.3$ to 2.3$)$ \\
\hline & 3 & $0.7(0.5 \text { to } 1.0)^{\star}$ & $0.3(0.1 \text { to } 1.1)^{\star}$ \\
\hline \multirow[t]{3}{*}{ Disinfectants } & 1 & $1.1(0.9$ to 1.3$)$ & $1.3(0.7$ to 2.2$)$ \\
\hline & 2 & $1.0(0.8$ to 1.2$)$ & $1.0(0.5$ to 1.9$)$ \\
\hline & 3 & $0.9(0.7$ to 1.1$)$ & $0.7(0.3$ to 1.4$)$ \\
\hline \multirow[t]{3}{*}{ Solvents or degreasers } & 1 & $0.8(0.6$ to 1.1$)$ & $0.6(0.2$ to 1.5$)$ \\
\hline & 2 & $0.9(0.6$ to 1.3$)$ & $0.6(0.2$ to 2.0$)$ \\
\hline & 3 & unstable model & \\
\hline \multirow[t]{3}{*}{ Pesticides } & 1 & $1.4(1.1 \text { to } 1.7)^{\star \star}$ & $2.7(1.5 \text { to } 4.8)^{\star \star}$ \\
\hline & 2 & $1.3(1.0 \text { to } 1.7)^{\star \star}$ & $2.2(1.0 \text { to } 4.9)^{\star \star}$ \\
\hline & 3 & $1.1(0.8$ to 1.6$)$ & $1.4(0.6$ to 3.8$)$ \\
\hline \multicolumn{4}{|l|}{ Covariates in model: $\ddagger$} \\
\hline \multicolumn{4}{|l|}{ Age: } \\
\hline $18-24$ & & $1.0(0.8$ to 1.4$)$ & \\
\hline $25-29$ & & 1.0 & \\
\hline $30-34$ & & $0.9(0.6$ to 1.2$)$ & \\
\hline$\geqslant 35$ & & $1.0(0.7$ to 1.5$)$ & \\
\hline Smoking during pregnancy & & $1.4(1.0 \text { to } 1.8)^{\star \star}$ & \\
\hline Alcohol use during pregnancy & & $0.8(0.6 \text { to } 1.0)^{\star}$ & \\
\hline \multicolumn{4}{|l|}{ Previous fetal loss: } \\
\hline \multicolumn{4}{|l|}{ Among pregnancies lasting $\leqslant 5.5$} \\
\hline months & & $24.6(14.5 \text { to } 41.8)^{\star \star}$ & \\
\hline \multicolumn{2}{|l|}{ Among pregnancies lasting $>5.5$} & & \\
\hline months & & $1.1(0.8$ to 1.4$)$ & \\
\hline Race and ethnicity: & & & \\
\hline White, non-Hispanic & & 1.0 & \\
\hline Hispanic & & $1.2(0.9$ to 1.6$)$ & \\
\hline Black & & $1.7(1.0 \text { to } 2.8)^{\star \star}$ & \\
\hline Asian, other & & $1.5(0.9 \text { to } 2.5)^{\star}$ & \\
\hline
\end{tabular}

$\star P$ value $<0.10$

$\star \star \mathrm{P}$ value $<0.05$

†Pesticides for ants, cockroaches, etc.

$\ddagger$ Covariate associations reported here are based on a model of exposure to garden pesticides for the first trimester; models for other exposure factors produced similar covariate associations. Ten counties of maternal residence were also included in all models. Season of conception was included in the models for residential and occupational exposure to pesticides. Per capita income was included in the model for video display terminal; RR for per capita income was 1.00 . $\S$ Relative to living $>1$ mile from commercial crops.

1982-4 California statewide fetal deaths of at least 20 weeks gestation and neonatal deaths within 24 hours of birth in non-urban counties. Complications of the placenta, cord, or membranes caused $37 \%$ of the deaths among the responders, which is slightly higher than the total cases and statewide percentages of $34 \%$ and $31 \%$, respectively. Congenital anomalies caused about $12 \%$ of the deaths in all case groups.

Adjusted results for stillbirths due to congenital anomalies (table 7) showed an OR of 2.4 associated with one month of occupational exposure to pesticides within the first eight
Table 6 Cause of death distribution of stillbirths or early neonatal death (respondents and total), 10 California counties, 1984, and California state stillbirths and early neonatal death in non-urban counties, 1982-4

\begin{tabular}{|c|c|c|c|c|c|c|}
\hline \multirow{2}{*}{$\begin{array}{l}\text { Cause of death } \\
\text { (ICD-9) }\end{array}$} & \multicolumn{2}{|c|}{$\begin{array}{l}\text { Cases who } \\
\text { responded }\end{array}$} & \multicolumn{2}{|c|}{ Total cases } & \multicolumn{2}{|c|}{$\begin{array}{l}\text { Statewide } \\
\text { non-urban } \\
\text { cases }\end{array}$} \\
\hline & $n$ & $(\%)$ & $n$ & (\%) & $n$ & $(\%)$ \\
\hline $\begin{array}{l}\text { Congenital } \\
\quad \text { anomalies (740 - } \\
759)\end{array}$ & 41 & (12) & 76 & (12) & 399 & (13) \\
\hline $\begin{array}{l}\text { Complications of } \\
\text { the placenta, } \\
\text { cord, or } \\
\text { membranes } \\
(762)\end{array}$ & 123 & (37) & 215 & (34) & 940 & (31) \\
\hline $\begin{array}{l}\text { Other maternal } \\
\text { causes of } \\
\text { perinatal } \\
\text { morbidity and } \\
\text { mortality }(760, \\
761,763)\end{array}$ & 37 & (11) & 72 & (11) & 456 & (15) \\
\hline $\begin{array}{l}\text { Other conditions } \\
\text { originating in the } \\
\text { perinatal period }\end{array}$ & & & & & & \\
\hline$(764-779)$ & 128 & (39) & 258 & $(41)$ & 1255 & (41) \\
\hline $\begin{array}{l}\text { Other causes of } \\
\text { mortality } \\
(001-739 \\
780-999)\end{array}$ & J & & & & & 1) \\
\hline Total & 332 & $(100)$ & 630 & (100) & 3072 & $(100)$ \\
\hline
\end{tabular}

*Nearly half of these other conditions were recorded as ill-defined or unspecified perinatal conditions.

weeks of pregnancy, and an OR of 1.7 for one month of home exposure to pesticides. Both of these associations were significant only at $P<0.1$. Exposure to extreme heat displayed a notable inverse association of 0.5 ; however, the $95 \%$ CI was wide (0.1 to 2.6 ).

Women occupationally exposed to pesticides for one month in the first trimester had a 1.7 times higher risk of stillbirth due to complications of the cord, placenta, and membranes than those not exposed (table 8), whereas exposure over the entire trimester versus no exposure was associated with about five times the risk. Relative risks for the second trimester were slightly lower than those for the first trimester. Borderline inverse associations were found for occupational exposure to video display terminals in the second and third trimesters (RR 0.6-0.7). For the first trimester, an inverse association of 0.5 was also found for exposure to occupational extreme heat and a suggestive positive association ( $R R$ 1.5) was found for residential exposure to lacquer or varnish, although both these $95 \%$ CIs contained 1.0 .

\section{Discussion}

Our findings of a positive association of occupational exposure to pesticides and stillbirths, after adjustment for all known and suspected confounders, is supported by the published literature. Our risk estimates of 1.32.4 for one month of exposure were similar to several published results. Savitz et al found an adjusted OR of 1.6 and Vaughan $e t$ al found an OR of 1.4 for stillbirths among women with agricultural jobs, whereas Taha and $\mathrm{Gray}^{3}$ reported an OR of 3.6 for stillbirths and perinatal deaths among female farmers exposed to pesticide spraying. McDonald et al 
Table 7 Adjusted association of selected exposures during the first two months of pregnancy and stillbirth or early neonatal death due to congenital anomalies: 10 counties in California, 1984

\begin{tabular}{|c|c|c|}
\hline Exposure factors & $\begin{array}{l}\text { Number of } \\
\text { exposed } \\
\text { cases }\end{array}$ & $\begin{array}{l}\text { Adjusted } O R \text { for } 1 \\
\text { month of exposure } \\
(95 \% \text { CI) }\end{array}$ \\
\hline \multicolumn{3}{|l|}{ Residential exposures: } \\
\hline Home pesticide applicationt & 8 & $1.7(1.0 \text { to } 2.9)^{\star}$ \\
\hline $\begin{array}{l}\text { Lived }<0.25 \text { miles from } \\
\text { crops } \oint\end{array}$ & 7 & $1.1(0.7$ to 1.8$)$ \\
\hline Paint application & 2 & $1.1(0.4$ to 2.9$)$ \\
\hline \multicolumn{3}{|l|}{ Lived $0.25-1$ mile from } \\
\hline crops $\$$ & 5 & $0.9(0.5$ to 1.5$)$ \\
\hline Garden pesticide application & 4 & $1.4(0.7$ to 2.8$)$ \\
\hline Pet pesticide application & 0 & Unstable model \\
\hline Lacquer or varnish & & \\
\hline application & 1 & $1.6(0.4$ to 6.7$)$ \\
\hline \multicolumn{3}{|l|}{ Occupational exposures: } \\
\hline Video display terminals & 1 & $0.7(0.2$ to 1.9$)$ \\
\hline Extreme heat & 1 & $0.5(0.1$ to 2.6$)$ \\
\hline Disinfectants & 2 & $1.1(0.5$ to 2.5$)$ \\
\hline Solvents or degreasers & 0 & Unstable model \\
\hline Pesticides & 3 & $2.4(1.0 \text { to } 5.9)^{\star}$ \\
\hline \multicolumn{3}{|l|}{ Covariates in model: $\ddagger$} \\
\hline \multicolumn{3}{|l|}{ Age: } \\
\hline $18-24$ & & $1.2(0.5$ to 2.6$)$ \\
\hline $25-29$ & & 1.0 \\
\hline $30-34$ & & $0.7(0.2$ to 2.0$)$ \\
\hline$\geqslant 35$ & & $1.6(0.5$ to 5.8$)$ \\
\hline Smoking in 1 st trimester & & $0.6(0.2$ to 1.9$)$ \\
\hline Alcohol use in 1st trimester & & $1.5(0.6$ to 3.6$)$ \\
\hline Previous fetal loss & & $1.0(0.4$ to 2.4$)$ \\
\hline \multicolumn{3}{|l|}{ Race and ethnicity: } \\
\hline White, non-Hispanic & & 1.0 \\
\hline Hispanic & & $1.8(0.9$ to 3.7$)$ \\
\hline Black, Asian, other & & $0.7(0.1$ to 3.4$)$ \\
\hline
\end{tabular}

$\star P \leqslant 0.10$

$\star \star \mathrm{P} \leqslant 0.05$.

†Pesticides for ants, cockroaches, etc.

$\mp$ Covariate associations reported here are based on the model of exposure to garden pesticides; models for other exposure factors produced similar covariate associations. Ten counties of maternal residence were also included in all models. Season of conception was included in the models for residential and occupational pesticide exposures. Per capita income was included in the model for video display terminal; OR for per capita income was 1 .

$\oint$ Relative to living $>1$ mile from commercial crops.

qTotal number of cases $=41$.

found a ratio of 5.6 for observed:expected stillbirths for women with agricultural job titles, but only a ratio of 1.1 for exposure to pesticides, fungicides, or herbicides regardless of job title. Goulet $e t a l^{9}$ reported similar mixed findings: OR 3.9 (NS) for stillbirth among women with agricultural jobs, but ORs of only 1.5-1.8 (NS) for exposure to pesticides or germicides from any job category. Goulet et al reported that most of the exposure to pesticides was experienced by nurses, waitresses, laundry workers, and cleaners. None of these early papers examined specific causes of fetal death.

Our generally modest inverse associations with occupational exposure to a video display terminal, of borderline significance, are supported by two relevant articles. McDonald et $a l^{12}$ found an RR of 0.82 (NS) for current exposure to video display terminals and an $R R$ of 0.71 (NS) for previous exposure. Nielsen and $B$ randt ${ }^{13}$ reported an adjusted $R R$ of 0.73 (NS) for any occupational exposure to a video display terminal during pregnancy versus none. We explored the possibility that exposure to a video display terminal was a surrogate for social class by adjusting for per capita income in the model; this proved not to change the results. Thus, the difference between cases and controls may reflect some confounding factors unmeasured in our data.

Our general finding of non-significant, inverse associations between stillbirth and occupational exposure to extreme heat is contrary to the one relevant study previously published. McDonald et $a l^{r}$ found a non-significant positive association between extreme heat and stillbirths. We do not suspect that exposure to extreme heat is truly a protective factor, and thus we presume that this finding reflects confounding factors unmeasured in this study.

No published reports could be traced on the use of home pesticide (for ants, cockroaches, etc) and stillbirths. Maternal residential exposure to pesticides in general, however, has been positively associated with stillbirth; reported RRs for all stillbirths (including perinatal deaths ${ }^{3}$ ) regardless of cause of death are consistent with our finding ( $R R$ 1.7) for stillbirths due to congenital anomalies: 1.5-1.6 from Savitz et al, ${ }^{2}$ 1.5-2.0 (NS) from Thomas et $a l,{ }^{4} 1.5$ for the highest exposure in the second trimester only by White et $a l,{ }^{5}$ and 1.6 (NS) in Taha and Gray. ${ }^{3}$

The association of several covariates and stillbirths differed in the two cause of death analyses, which is reasonable as congenital anomalies and complications of the placenta, cord, and membranes are potentially aetiologically different. Previous fetal loss was an important predictor in the models for deaths due to complications of the placenta, cord, and membranes, but not in the congenital anomaly models. This discrepancy for previous fetal loss might be explained by prenatal diagnostic tests-for example, amniocentesis-that lead to elective abortions among women who are carrying fetuses with anomalies. Within the analysis of stillbirths due to complications of the placenta, cord, and membranes, the magnitude of the association with previous pregnancy loss among deliveries that occurred within 5.5 months of gestation ( $R R$ 69) indicates that later losses may be aetiologically different from earlier ones. Because most of the women with previous fetal losses and gestational ages $<5.5$ months were black, we reran the models for stillbirths due to complications of the placenta, cord, and membranes without controlling for race and ethnicity; these models produced very similar coefficients. Smoking during pregnancy was moderately associated with stillbirths due to complications of the placenta, cord, and membranes (RR 1.4, $95 \%$ CI 0.9 to 2.3 ) and was not associated with stillbirths due to congenital anomalies. A positive association has been previously reported between smoking and stillbirths from all causes of death. ${ }^{192124-26}$ As expected, mothers over the age of 35 were at greater risk for stillbirth due to congenital anomalies (OR 1.6, 95\% CI 0.5 to 5.8) than younger mothers. Hispanic ethnicity was positively associated with the models of congenital anomalies (OR 1.8, 95\% CI 0.9 to 3.7), but not in the models of placenta, cord, and membrane complications. For the all cause of death analysis only, black (versus white or non-Hispanic) race had a positive association with stillbirths (RR $1.7,95 \%$ CI 1.0 to 2.8 ), 
Table 8 Adjusted association of exposures by individual trimester and stillbirths or early neonatal death due to complications of the cord, placenta, and membranes: 10 counties in California, 1984

\begin{tabular}{|c|c|c|c|c|}
\hline Exposure factors & Trimester & $\begin{array}{l}\text { Number of } \\
\text { exposed } \\
\text { cases }\end{array}$ & $\begin{array}{l}\text { Adjusted } R R \text { for } 1 \\
\text { month of exposure } \\
(95 \% \text { CI) }\end{array}$ & $\begin{array}{l}\text { Adjusted } R R \text { for } 3 \\
\text { months of exposure } \\
(95 \% \text { CI) }\end{array}$ \\
\hline \multicolumn{5}{|l|}{ Residential exposures: } \\
\hline \multirow[t]{3}{*}{ Home pesticide application $\dagger$} & 1 & 18 & $1.1(0.9$ to 1.5$)$ & $1.4(0.6$ to 3.1$)$ \\
\hline & 2 & 13 & $0.7(0.5 \text { to } 1.0)^{\star}$ & $0.4(0.2 \text { to } 0.1)^{\star}$ \\
\hline & 3 & 7 & $0.8(0.7 \text { to } 1.0)^{\star}$ & $0.6(0.3 \text { to } 1.1)^{\star}$ \\
\hline \multicolumn{5}{|l|}{ Lived $<0.25$ miles from } \\
\hline \multirow[t]{3}{*}{ crops $₫$} & 1 & 24 & $1.0(1.0$ to 1.1$)$ & $1.0(0.9$ to 1.2$)$ \\
\hline & 2 & 26 & $1.0(1.0$ to 1.1$)$ & $1.0(0.9$ to 1.2$)$ \\
\hline & 3 & 21 & $1.0(0.9$ to 1.2$)$ & $1.11(0.80$ to 1.6$)$ \\
\hline \multirow[t]{3}{*}{ Paint application } & 1 & 6 & $1.2(0.8$ to 1.8$)$ & $1.6(0.5$ to 5.4$)$ \\
\hline & 2 & 16 & $1.2(0.9$ to 1.6$)$ & $1.7(0.7$ to 4.3$)$ \\
\hline & 3 & 9 & $1.0(0.8$ to 1.3$)$ & $1.1(0.5$ to 2.2$)$ \\
\hline \multicolumn{5}{|l|}{ Lived $0.25-1$ mile from } \\
\hline \multirow[t]{3}{*}{ crops $\$} & 1 & 16 & $1.1(1.0 \text { to } 1.1)^{\circ}$ & $1.2(1.0 \text { to } 1.4)^{\circ}$ \\
\hline & 2 & 17 & $1.0(1.0$ to 1.1$)$ & 1.1 (1.0 to 1.3$)$ \\
\hline & 3 & 18 & $1.0(0.9$ to 1.1$)$ & $1.0(0.7$ to 1.4$)$ \\
\hline \multirow[t]{3}{*}{ Garden pesticide application } & 1 & 10 & $1.1(0.8$ to 1.4$)$ & $1.1(0.4$ to 2.8$)$ \\
\hline & 2 & 12 & $1.0(0.8$ to 1.4$)$ & $1.1(0.5$ to 2.7$)$ \\
\hline & 3 & 5 & $0.9(0.7$ to 1.2$)$ & 0.7 (0.3 to 1.5$)$ \\
\hline \multirow{3}{*}{ Pet pesticide application } & 1 & 12 & $1.2(0.9$ to 1.6$)$ & $1.7(0.8$ to 4.1$)$ \\
\hline & 2 & 16 & $1.2(1.0$ to 1.6$)$ & $1.9(0.8$ to 4.0$)$ \\
\hline & 3 & 11 & $1.1(0.9$ to 1.3$)$ & $1.3(0.9$ to 2.1$)$ \\
\hline \multicolumn{5}{|l|}{ Lacquer or varnish } \\
\hline \multirow[t]{3}{*}{ application } & 1 & 2 & $1.5(0.8$ to 2.8$)$ & $3.6(0.5$ to 23.0$)$ \\
\hline & 2 & 3 & $1.4(0.7$ to 2.6$)$ & $2.5(0.4$ to 16.9$)$ \\
\hline & 3 & 5 & $1.1(0.8$ to 1.6$)$ & $1.5(0.6$ to 3.8$)$ \\
\hline \multicolumn{5}{|l|}{ Occupational exposures: } \\
\hline \multirow[t]{3}{*}{ Video display terminals } & 1 & 5 & $0.8(0.5$ to 1.1$)$ & $0.5(0.2$ to 1.3$)$ \\
\hline & 2 & 5 & $0.7(0.4 \text { to } 1.0)^{\star}$ & $0.3(0.1 \text { to } 1.0)^{\star}$ \\
\hline & 3 & 2 & $0.6(0.3 \text { to } 1.0)^{\star}$ & $0.2(0.0 \text { to } 1.1)^{\star}$ \\
\hline \multirow[t]{3}{*}{ Extreme heat } & 1 & 3 & $0.5(0.2$ to 1.4$)$ & $0.1(0.0$ to 2.4$)$ \\
\hline & 2 & 3 & $0.8(0.4$ to 1.5$)$ & $0.5(0.1$ to 3.5$)$ \\
\hline & 3 & 0 & unstable model & \\
\hline \multirow[t]{3}{*}{ Disinfectants } & 1 & 6 & $1.1(0.8$ to 1.5$)$ & $1.4(0.6$ to 3.4$)$ \\
\hline & 2 & 5 & $1.0(0.7$ to 1.4$)$ & $1.0(0.4$ to 2.9$)$ \\
\hline & 3 & 2 & $0.9(0.6$ to 1.2$)$ & $0.7(0.3$ to 1.8$)$ \\
\hline \multirow[t]{3}{*}{ Solvents or degreasers } & 1 & 1 & $0.7(0.3$ to 1.3$)$ & $0.3(0.0$ to 2.1$)$ \\
\hline & 2 & 1 & $0.6(0.3$ to 1.5$)$ & $0.2(0.0$ to 3.1$)$ \\
\hline & 3 & 0 & unstable model & \\
\hline Pesticides & 1 & 7 & $1.7(1.3 \text { to } 2.3)^{\star \star}$ & $4.8(2.0 \text { to } 11.4)^{\star \star}$ \\
\hline & 2 & 6 & $1.6(1.1 \text { to } 2.3)^{\star \star}$ & $4.2(1.4 \text { to } 12.0)^{\star \star}$ \\
\hline & 3 & 2 & $1.2(0.8$ to 1.8$)$ & $1.7(0.5$ to 5.7$)$ \\
\hline Covariates in model: $\ddagger$ & & & & \\
\hline Age: & & & & \\
\hline $18-24$ & & & $1.0(0.7$ to 1.5$)$ & \\
\hline $25-29$ & & & 1.0 & \\
\hline $30-34$ & & & $0.7(0.4$ to 1.3$)$ & \\
\hline$\geqslant 35$ & & & $0.8(0.4$ to 1.7$)$ & \\
\hline Smoking during pregnancy & & & $1.4(0.9$ to 2.3$)$ & \\
\hline Alcohol use during & & & & \\
\hline pregnancy & & & $0.8(0.5$ to 1.2$)$ & \\
\hline Previous fetal loss: & & & & \\
\hline Among pregnancies & & & & \\
\hline lasting $\leqslant 5.5$ months & & & $69(25 \text { to } 191)^{\star \star}$ & \\
\hline Among pregnancies & & & & \\
\hline lasting $>5.5$ months & & & $1.3(0.8$ to 2.1$)$ & \\
\hline Race and ethnicity & & & & \\
\hline White, non-Hispanic & & & 1.0 & \\
\hline Hispanic & & & $1.2(0.8$ to 1.8$)$ & \\
\hline Black & & & $0.9(0.3$ to 2.6$)$ & \\
\hline Asian, other & & & $1.8(0.8$ to 4.5$)$ & \\
\hline
\end{tabular}

$\star \mathrm{P}<0.10$.

$\star \star \mathrm{P}<0.05$

†Pesticides for ants, cockroaches, etc.

$\ddagger$ Covariate associations reported here are based on the model of exposure to garden pesticide for the first trimester; models for other exposure factors produced very similar covariate associations. Ten counties of maternal residence were also included in all models. Season of conception was included in the models for residential and occupational pesticide exposures. Per capita income was included in the model for video display terminal; RR for per capita income was 1.00 . §Relative to living $>1$ mile from commercial crops.

TTotal number of cases $=123$. stillbirths and occupational or residential exposures that did examine specific causes of death combined all women exposed to any exposures of interest into one hazard group, and thus their findings are not comparable with ours. ${ }^{27}$ Also, only two cited publications ${ }^{45}$ examined time specific exposure windows, as was done here.

One limitation of our study is the two to four year span between the delivery and completion of the questionnaire, which was partially due to the time needed by the state vital statistics system to create the electronic data tape used to ascertain addresses. Errors in assigning specific exposures to specific months are possible, and would be expected to lead to non-differential misclassification. Also, misclassification due to recall bias was possible, as is true for all case-control studies relying on self reports of exposure. Although differential recall has been noted for some exposures, ${ }^{28}$ previous research has generally found errors of recall to be similar among cases and controls in reproductive studies. ${ }^{29}{ }^{30}$ This would bias risk estimates of dichotomous exposures toward the null. In these data, we do not suspect misreporting of exposures to have substantially influenced our results because women did report illegal behaviours - such as use of marijuana-and the women's work histories tended to be steady through the second trimester, ${ }^{14}$ as expected.

Another limitation of the study was the inability to locate $20 \%$ of the selected study subjects: those who had moved shortly after delivery, left no forwarding address, and lacked a California drivers' licence. As migrant workers and other highly mobile people were underrepresented, the findings can be viewed as generalisable to moderately non-mobile populations. It is possible, however, that bias was due to the overall response rate of $68 \%$, if non-response was related to a given exposure conditional on cases or control status. We noted that the response rate was equivalent for cases and controls, and we did not have exposure data on the non-respondents with which to evaluate this potential bias.

A third limitation was the small sample size. Although the all cause of death analysis had a minimum of 10 exposed cases, 10 exposed controls, and 25 exposed women combined, the two specific cause of death analyses did not meet these same minimum requirements. Thus, precision of our estimates is low, especially among the smaller case group analyses.

A fourth limitation is our exposure measurement of yes or no in each month of pregnancy. Thus, it is unknown whether there was exposure one day of the month or all days of the month. Further details on specific exposure to pesticides in these data are being analysed.

Misclassification of some of the potential confounders - for example, maternal age-due to inaccurate vital statistics was also a possibility. Also, underreporting of fetal deaths in gestation weeks $20-28$ was likely. Based on research by Goldhaber et al, ${ }^{31}$ we estimate that in this analysis and is important because of potentially different aetiologies for different causes of death. The one publication on which was also found by Copper et $a l^{19}$ and Litonly). ${ }^{23}$

None of the scientific literature cited in this report examined individual exposures for 
one fifth of eligible cases were missing from our data due to underreporting of stillbirths, most notably those in $20-28$ weeks of gestation. It is likely that the unreported fetal deaths were largely infants weighing $<500 \mathrm{~g}$. Whether or not the lowest birthweight cases included in this study were representative of all such stillbirths for the exposures we examined cannot be ascertained. On the other hand, inclusion of stillbirths in gestational ages $20-28$ weeks, by contrast with studies with a minimum gestational age of 28 weeks $^{24712212225}$ is a strength considering that about $30 \%$ of our cases were from this early period of gestation.

The primary hypothesis of the original casecontrol study was to examine the effect on stillbirths and early neonatal deaths of maternal exposures to pesticide in the environment during pregnancy. Hence, many of these results should be considered to generate hypotheses, rather than be definitive and conclusive on their own. However, the results on occupational exposure to pesticides deserve serious attention. Firstly, they are supported by previous studies. Secondly, the associations are stable for all three case groups. Larger studies with cause of death, exposure time windows, and specific pesticide formulations are now warranted to target specific reproductive toxins and their modes of action.

Any analysis of single risk factors tends to oversimplify reality, in which several factors in combination may result in a particular reproductive outcome rather than any one factor causing the demise of the fetus. The current study, by taking a broad approach, provides $(a)$ perspective on a range of exposures that occur throughout pregnancy, $(b)$ clues as to potential risk factors that are worthy of future study, and (c) meaningful information on the relevant time windows for specific outcomes and exposures.

Our findings expand on the current knowledge of the potential harmful effect of occupational exposure to pesticides during pregnancy by (a) identifying two cause of death categories with positive associations (congenital anomalies, and complications of the placenta, cord, and membranes), and (b) narrowing the time window of concern, which has relevance both for individual women and future research. Methodologically, this study of stillbirths is unique in its inclusion of specific cause of death analyses and examination of time specific exposure windows. Our results highlight the benefit of collecting time specific exposures for the analysis of reproductive outcomes, as the associations examined varied by time window. Lastly, our statistical approach considered the need for time adjusted analyses when the exposure opportunity varies between cases and controls. This was rarely performed in the earlier relevant research on stillbirths.

This work was partially supported by grant ES03767 from the National Institute of Environmental Health Sciences, a University of North Carolina at Chapel Hill University Research Council award, a University of North Carolina at Chapel Hill Faculty Development award (IBM fund award), the NICHD Carolina Population Center training grant 2-T32-HD0716816, and the NIOSH cooperative agreement U07/CCU906162 for agricultural health and safety. We thank Dr Steven Samuels,
James Singleton, and Susan Lutzenhiser for their contributions to study design, data collection, and database development, David A Savitz for his valuable comments on the manuscript and Andrew Olshan for helpful suggestions on the analysis of congenital anomalies.

1 National Center for Health Statistics. Health, United States, 1991. Hyattsville, MD: US DHHS, 1991. (Publ No (PHS) 92-1232; table 18.)

2 Savitz DA, Whelan EA, Kleckner RC. Self-reported exposure to pesticides and radiation related to pregnancy outcome: results from national natality and fetal mortality surveys. Public Health Rep 1989;104:473-7.

3 Taha TE, Gray RH. Agricultural pesticide exposure and perinatal mortality in central Sudan. Bull World Health perinatal mortality in
Organ 1993;71:317-21.

4 Thomas DC, Petitti DB, Goldhaber M, Swan S, Rappaport E, Hertz-Picciotto I. Reproductive outcomes in relation to malathion spraying in the San Francisco Bay area, 1981-2. Epidemiology 1992;3:32-9.

5 White F, Cohen FG, Sherman G, McCurdy R. Chemicals birth defects and stillbirths in New Brunswick: associations with agricultural activity. Can Med Assoc $₹$ 1988;138:11724.

6 Vaughan TL, Daling JR, Starzyk PM. Fetal death and maternal occupation. F Occup Med 1984;26:676-8.

7 McDonald AD, McDonald JC, Armstrong B, Cherry NM, Cote R, Lavoie J, et al. Fetal death and work in pregnancy. Br f Ind Med 1988;45:148-57.

8 Sadler TW. Langman's medical embryology. 7th ed. Baltimore, MD: Williams and Wilkins, 1995:140.

9 Goulet L, Theriault G. Stillbirth and chemical exposure of pregnant workers. Scand $\mathcal{F}$ Work Environ Health 1991;17: pregnant

10 Mukametova IM, Vozovaya MA. Reproductive power and the incidence of gynecological affections in female workers exposed to the combined effect of benzine and chlorinated hydrocarbons. Gigiena Truda Professional 'nye Zabolevaniya 1972;16:6-9.

11 Syrovadko ON. Working conditions and health status of women handling organo silicon varnishes containing toluene. Gigiena Truda Professional 'nye Zabolevaniya 1977; 12:15-9.

12 McDonald AD, McDonald JC, Armstrong B, Cherry N, Nolin AD, Robert D. Work with visual display units in pregnancy. Br F Ind Med 1988;45:509-15.

13 Nielsen CV, Brandt LPA. Fetal growth, preterm birth, and infant mortality in relation to work with video display infant mortality in relation to work with video display terminals during

14 Hertz-Picciotto I, Pastore LM, Beaumont JJ. Timing and patterns of exposures during pregnancy and their implications for study methods. Am $\mathcal{F}$ Epidemiol 1996;143:597607.

15 Hertz-Picciotto I, Swan SH, Neutra RR, Samuels SJ. Spontaneous abortions in relation to consumption of tap water: an application of methods from survival analysis to a pregnancy follow-up study. Am $\mathcal{F}$ Epidemiol 1989;130:79-93.

16 Poole C. Exposure opportunity in case-control studies. Am f Epidemiol 1986;123:352-8.

17 Breslow NE, Day N. Statistical methods in cancer epidemiology. Vol II - The design and analysis of cohort studies. Lyon: ogy. Vol Tional Agency for Research on studies. Lyon: (IARC Sci Publ No 82.)

18 Preston DL, Lubin JH, Pierce DA, McConney ME. Epicure user's guide. Seattle: Hirosoft, 1993

19 Copper RL, Goldenberg RL, DuBard MB, Davis RO. Risk factors for fetal death in white, black, and Hispanic women. Obstet Gynecol 1994;84:490-5.

20 Cnattingius S, Haglund B, Meirik O. Cigarette smoking as risk factor for late fetal and early neonatal death. $B M F$ 1988;297:258-61.

21 Raymond EG, Cnattingius S, Kiely J. Effects of maternal age, parity, and smoking on the risk of stillbirth. $\mathrm{Br} \mathcal{F}$ Obstet Gynaecol 1994;101:301-6.

22 Kumar $R$, Singhi $S$. Risk factors for stillbirths in a rural community. Indian $\mathcal{F}$ Pediatr 1992;59:455-61.

23 Little RE, Weinberg CR. Risk factors for antepartum and intrapartum stillbirth. Am $\mathcal{F}$ Epidemiol 1993;137:1177-89. intrapartum stillbirth. Am $\mathcal{F}$ Epidemiol 1993;137:1177-89.
Meyer MB, Tonascia JA, Buck C. The interrelationship of maternal smoking and increased perinatal mortality with other risk factors: further analysis of the Ontario perinatal mortality study, 1960-1. Am f Epidemiol 1976;100:443-52.

25 Walles B, Tyden T, Herbst A, Ljungblad U, Rydhstrom H. Maternal health care program and markers for late fetal death. Acta Obstet Gynecol Scand 1994;73:773-8.

26 Williams MA, Mittendorf R, Lieberman E, et al. Cigarette smoking during pregnancy in relation to placenta previa. Am $\mathcal{F}$ Obstet Gynecol 1991;165:28-32.

27 Zhang J, Cai W. Risk factors associated with antepartum fetal death. Early Hum Dev 1992;28:193-200.

28 Werler MM, Pober BR, Nelson K, Holmes LB. Reporting accuracy among mothers of malformed and nonmalformed infants. Am $\mathcal{F}$ Epidemiol 1989;129:415-21.

29 Harlow SD, Linet MS. Agreement between questionnaire data and medical records. Am ₹ Epidemiol 1989;129:23348.

30 MacKenzie SG, Lippman A. An investigation of report bias in a case-control study of pregnancy outcome. Am $\mathscr{f}$ Epidemiol 1989;129:65-75.

31 Goldhaber MK. Fetal death ratios in a prospective study compared to state fetal death certificate reporting. $A m \mathcal{F}$ Public Health 1989;79:1268-70. 